\title{
Constitution Embodiment
}

\author{
Alexander Albert Jeuk \\ Independent Researcher, Germany \\ Graduate of the University of Cincinnati \\ alexander.jeuk@gmail.com
}

Received 20 March 2017; accepted 25 July 2017.

\begin{abstract}
In this paper I analyze constitution embodiment, a particular conception of embodiment. Proponents of constitution embodiment claim that the body is a condition of the constitution of entities. Constitution embodiment is popular with phenomenologically-inspired Embodied Cognition (PEC), including research projects such as Enactivism (Noë, 2004, 2012; Thompson, 2007) and Radical Embodied Cognitive Science (Chemero, 2009). Unfortunately, PEC's use of constitution embodiment is neither clear nor coherent; in particular, PEC uses the concept of constitution embodiment so that a major inconsistency is entailed. PEC conceives of the body in a transcendental sense as a condition of the constitution of entities, and, in an ontic sense, as a scientifically describable entity. Yet, a condition of the constitution of entities cannot be itself an entity-rather, it is the very condition of the possibility of an entity. This inconsistency entails further problems, among them PEC's misguided focus on the location of the embodied mind. In order to correct these mistakes, I develop a conception of constitution embodiment based on the work of Heidegger (1962), Husserl (1989) and to a lesser degree Merleau-Ponty (2012). This has two purposes. First, it provides the conceptual groundwork to secure the status of PEC as a consistent and coherent research project and to clarify PEC's conception of the relationship between phenomenology and the sciences. In that spirit, my approach provides further guidelines for fruitful research alliances between PEC and other research programs such as Grounded Cognition (Gallese \& Lakoff, 2005) and identifies current research alliances, such as those with Radical Enactivism (2013), as undesirable. Second, my account provides an elaborate concept of constitution embodiment that can function as the basis for more sophisticated work in the future.
\end{abstract}

Keywords: embodiment; constitution; phenomenology; embodied cognition; conceptual inconsistency; philosophical methodology. 


\section{Acknowledgments}

I would like to thank the University of Cincinnati and the Charles Phelps Taft Research Center for the generous funding that allowed me to complete my research. I would like to thank in particular Friderike Spang, Anthony Chemero, Peter Langland-Hassan and Thomas Polger for their valuable feedback on the paper. I want to extend my thanks to the two anonymous referees who helped me substantially to enhance the quality of the paper.

\section{Introduction}

As is well known by now, "embodiment" can mean quite different, at times opposing things (Haugeland, 1998; Wilson, 2002; Gallese \& Lakoff, 2005; Clark, 2008a; Barsalou, 2008; Goldman \& de Vignemont, 2009; Kiverstein \& Clark, 2009; Gallagher, 2011; Alsmith \& de Vignemont, 2012; Kiverstein, 2012; Vörös, Froese, \& Riegler, 2016; Vörös $\&$ Gaitsch, 2016). In the following, I examine one particular kind of embodiment that I call, for lack of a better term, "constitution embodiment."1 Proponents of "constitution embodiment" state that the body is constitutive for the objects of experience and thought. ${ }^{2}$ As Husserl states ${ }^{3}$ :

We need only consider how a thing exhibits itself as such, according to its essence, in order to recognize that such an apprehension must contain, at the very outset, components which refer back to the subject, specifically the human (or, better: animal) subject in a fixed sense. (Husserl, 1989, p. 61)

\footnotetext{
${ }^{1}$ What I call "constitution embodiment" has various predecessors in the phenomenological tradition that are highly similar to the conception that I put forward in this paper and they go by different names. These conceptual predecessors have significantly more detail to them than the concept that I propose here, and I invite the reader to refer to them to receive a more complete understanding of the matter of constitution and embodiment than this paper can provide. Husserl, for instance, differentiates his conception of the lived body, the ontological function of which corresponds to constitution embodiment, further into "Aussenleiblichkeit" ("lived body exteriority") and "Innenleiblichkeit" ("lived body interiority") (Husserl, 1989) to account for the bi-directional co-constitution relationship between subject and object, which is beyond the scope of this paper (though see my short discussion in footnote 17). Merleau-Ponty uses, among many other expressions, the terms "phenomenal body," "body schema," "vehicle of being in the world" (Merleau-Ponty, 2012, p. 82), "my body is my perspective on the world" (Merleau-Ponty, 2012, p. 70) to convey what I describe with "constitution embodiment." Henry accounts for what I propose here with the term "transcendental body" (see also "auto-affectivity") (Henry, 1975, p. 73). For a good overview of these different conceptions and terms, please see Taipale (2014).

${ }^{2}$ I use the terms "constitutive" and "co-constitutive" interchangeably in this paper. When I talk about constitution I never assume that constitution is happening unidirectionally from the embodied subject to the world, but that the constitution of our experience and understanding of objects is bi-directional. In that sense, embodiment is co-constitutive of our experience together with the world (yet keep in mind that "world" does not refer here to the positive world of science, but to whatever non-bodily $x$ that co-constitutes our experience in tandem with our embodiment). I focus in this paper primarily on the constitutive contribution of the body. A focus on 'worldly' constitutive factors would go beyond the scope of this paper.

${ }^{3}$ In this quote Husserl speaks only of the human subject. However, as we can see below, the quote is from the second book of his Ideas which is about how the lived body co-constitutes our experience.
} 
The concept of constitution embodiment has been most prominently developed by Husserl (1989) and by Merleau-Ponty (2012) in the context of their discussion of the Leib (lived body) and phenomenological body, respectively. As we will see, Heidegger (1962) has developed his own conception of the term in the context of his treatment of care. ${ }^{4}$

Constitution embodiment is the opposite of what we might want to refer to as "body neutrality." Body neutrality is a particular version of what Husserl and Merleau-Ponty call the "natural" or "dogmatic attitude," respectively. ${ }^{5}$ According to the natural attitude, the world is as it appears, independent of the invariant structures that organize our experience; i.e., the world is constitutively independent of a conscious agent. By extension, body neutrality states that the body is not a constitutive condition of our experience and understanding of entities.

As I show in section 2.1, constitution embodiment has become popular again due to the work of Enactivists (Varela, Thompson, \& Rosch, 1991; Noë, 2004, 2012; Thompson, 2007; Thompson \& Stapleton, 2009; Stapleton, 2013) and proponents of Radical Embodied Cognitive Science, henceforth RECS (Chemero, 2009; Rietveld \& Kiverstein, 2014). But, as I suggest, constitution embodiment should be also of interest to all other proponents of phenomenologically inspired Embodied Cognition (henceforth PEC); particularly to those who have in their writing stressed the importance of Husserl's concept of "Leib," or Merleau-Ponty's concept of "body schema." 6

Despite its regained popularity, neither the concept of constitution embodiment nor its entailments are particularly well spelled out by proponents of PEC. My discussion of Husserl, Merleau-Ponty and Heidegger in sections 2.2 and 2.3 demonstrates this lack of conceptual clarity in contemporary work. I provide in these sections a detailed discussion of these classic authors to provide a sufficiently complex, consistent and explicit conception of constitution embodiment. I focus hereby on two aspects of constitution embodiment. First, in accord with Husserl's and Merleau-Ponty's work, I show how our embodiment is co-constitutive of the spatiality of the objects that we can understand and experience. Second, I examine, following Heidegger's work on the care structure, how our embodiment constitutes the significance of the objects - their "whatness" - that we encounter in the world.

\footnotetext{
${ }^{4}$ It needs to be added that Merleau-Ponty's use of the relevant terminology above is less straightforward than Husserl's use and in general not as clear as one would desire. This circumstance partially reflects why my own elaborations on a positive concept of constitution embodiment focus rather on Husserl's and Heidegger's work than on Merleau-Ponty's work.

${ }^{5}$ For a recent discussion of the natural attitude see also Dreyfus's and Taylor's (2015) conception of the "neutrality condition" of the "mediational picture."

${ }^{6}$ Some contemporary writings (Zahavi, 2005; Fuchs, 2011) that seek to introduce phenomenology to a primarily analytically educated audience treat the Leib or lived body primarily as the body as it is experienced in "qualitative experience," or as something that can be researched through the "first-person perspective." This approach should be considered with caution, since these categories that are applied to the Leib here are those of Analytic Philosophy and, for good reasons, they are alien to the very idea of Phenomenology. If I use the terms "Leib" or "lived body" in the following, I do not make any such connotations, but primarily treat the Leib as a condition of the constitution of entities.
} 
Developing a sufficient concept of constitution embodiment has two purposes. First, it provides PEC with an elaborate concept of constitution embodiment that can function as the basis for more sophisticated work. Second, it helps to identify conceptual problems with the use of the term in PEC. These conceptual problems are manifold and severe, as my discussion in section 3 demonstrates. As such, a proper concept of constitution embodiment is the necessary conceptual groundwork to secure the status of PEC as a consistent and coherent research project.

Section 3.1 provides a demonstration of how proponents of PEC use the concept of constitution embodiment in a way that a major inconsistency arises. I show that many authors confuse what is a transcendental claim about the structures that constitute a world of entities with a positive claim about entities themselves. Constitution embodiment is a condition of having a world for a person. As such, it cannot be examined as an entity in the world - a physical body - as the scientifically inspired work of various contemporary champions of constitution embodiment suggests, because it is co-constitutive of a scientifically examinable world and of the entities in it. Here, a proper concept of constitution embodiment allows us to demarcate clearly between philosophical and scientific claims. Whatever abstract reasons have been given in the methodological debates about the relationship between science and philosophy (Petitot et al., 1999; Dreyfus, 2007; Noë, 2005, 2011; Wheeler \& Kiverstein, 2012; Carel \& Meacham, 2013; Fernandez, 2016), the present discussion shows concretely how the relationship has to be conceived of a given concrete philosophical problem.

Further, I show in section 3.2 that the focus on the location of the embodied mind in PEC is a result of confusing constitution embodiment as a constitutive condition of entities with a spatially extended entity. In particular, if, as I will show in section 2.2, constitution embodiment is itself a co-constituting condition of the spatiality of objects, the embodied mind cannot be located in space itself, as claims about the extendedness of the mind suggest.

In order to highlight the significance of these conceptual inconsistencies, I show in section 3.3 that claims about the location of the embodied mind are empty conceptual claims. If claims about the location of the embodied mind were meaningful, we could derive conceptual entailments about the structure of the mind from them. As I show with reference to the work of Thompson (2007) and Hutto and Myin (2013), respectively, this is not the case.

Finally, section 3.4 contains a short discussion about desirable philosophical and scientific research alliances within PEC, i.e., a short discussion about the work that should be included and discussed within the boundaries of the paradigm. If researchers are concerned with matters of constitution, I suggest that a productive research alliance should be founded not on an examination of the alleged location of the embodied mind, but on investigations into how the embodied mind constitutes or at least structures the world of an organism. The unfruitful focus on location has lead PEC astray. The proper argumentative opponent of PEC has to be body neutrality - the claim that the body does not constitute the objects of our experience and understanding. Contrary to that, the emphasis on a rejection of internalism, even though correct, often enough leaves body neutrality untouched 
or might even support it. Accordingly, PEC should overcome its opposition to grounded cognition (Barsalou, 1999; Gallese \& Lakoff, 2005), metaphor theory (Johnson \& Lakoff, 1999; Boroditsky \& Ramscar, 2002) and other projects that reject body neutrality, and reconsider how much it actually has in common with projects such as Radical Enactivism (Hutto \& Myin, 2013) that leave body neutrality untouched.

There are plenty of reasons to accept constitution embodiment as a condition of the possibility of things showing up as they do. They range from general, complex considerations that characterize the work of Husserl, Heidegger and Merleau-Ponty, to more specific claims, such as that constitution embodiment is a condition of the possibility of action (Heidegger, 1962; Noë, 2004; Chemero, 2009; Merleau-Ponty, 2012). I will not further discuss these claims, though I mention reasons for accepting constitution embodiment when it fits the structure of the argument. Rather, I take it for granted that constitution embodiment is a condition of the possibility of objects and spell out what is conceptually entailed if we accept it.

\section{Constitution Embodiment}

\subsection{PEC and Constitution Embodiment}

Various proponents of PEC, in particular Enactivists as well as proponents of RECS, have provided their own take on constitution embodiment in terms of enaction, sense-making and affordances (Varela et al., 1991; Noë, 2004, 2012; Thompson, 2007; Chemero, 2009; Thompson \& Stapleton, 2009; Kiverstein, 2012; Rietveld \& Kiverstein, 2014). Particularly Enactivists have stressed the constitutive role of the embodied organism for experience and understanding.

A cognitive being's world is not a prespecified, external realm, represented internally by its brain, but a relational domain enacted or brought forth by that being's autonomous agency and mode of coupling with the environment. (Thompson, 2007, p. 13)

Similarly, Kiverstein:

The body enactivist understands embodiment in terms of bodily skills we draw on all the time when we act unreflectively, and in virtue of which we can encounter situations that are meaningful. (Kiverstein, 2012, p. 13)

For Enactivists, the world is not passively given, but brought forth by an embodied organism. The main case to which Enactivists constantly refer to exemplify enaction or sensemaking, is that of a simple organism, like an amoeba or bacterium, that enacts its world. Among the objects of the organism's world, sugar is the most significant one.

Sugar is significant to these organisms and more of it is better than less because of the way their metabolism chemically realizes their autonomous organization. The significance and valence of sugar are not intrinsic to the sugar molecules; they are relational features, tied to the bacteria as autonomous unities. (Thompson \& Stapleton, 2009, pp. 24-25) 
According to Thompson and Stapleton, sugar, as sugar-as-food, is at least co-constituted by an embodied organism in that sugar-as-food is only significant for an embodied being that uses sugar in a particular way - in this case as food.

Alva Noë $(2004,2012)$ has made similar claims about how the body constitutes the objects of experience and understanding. However, he is less explicit about this than Thompson and Stapleton. Yet, we can clearly see a conception of constitution embodiment at play in his enactivist account of experience and understanding.

Like other enactivists, Noë identifies with "existential phenomenology"-Heidegger and Merleau-Ponty in particular - in that he rejects the idea that humans are "detached representer(s) and interpreter(s)" of their environment (Noë, 2012, p. 8). As we will see later, this means for existential phenomenologists not only that we are primarily active agents, but that we also co-constitute the world we live in based on our embodiment.

Noë argues that we need to achieve presence of the world; we need to make the objects of our experience present to us - they are not merely given to us. Differently put, we spontaneously contribute something to the world so that it shows up for us. In many ways following Kant and the phenomenological tradition, Noë (2012, p. 20) claims that "knowledge, understanding, skills" are what we contribute to the world to make it present.

Importantly, Noë argues that knowledge, understanding and skill are dependent on one's embodiment in a twofold sense. Understanding, knowledge and skill are primarily sensorimotor understanding, sensorimotor knowledge and sensorimotor skill (Noë 2004). Yet, sensorimotor skill is not an abstract form of skill; it always refers back to a particular body. As Noë states:

If perception is in part constituted by our possession and exercise of bodily skills ... then it may also depend on our possession of the sort of bodies that can encompass those skills, for only a creature with such a body could have those skills. To perceive like us, it follows, you must have a body like ours. (Noë, 2004, p. 25)

As we will see below, this idea resembles closely Merleau-Ponty's considerations that the world has to be reflective of our embodied skills so that it can show up in the first place. In accord with Noë's statements about the world-disclosing role of experience and perception as well as his statements about constitution embodiment, Noë makes clear that we "enact content" based on our embodied skill (Noë, 2004, p. 100) and that this embodied skill is not merely a causal perceptual ability that represents a given, but the spontaneous precondition of having "world-presenting sensory experience" (Noë, 2004, p. 117).

More recently Noë has specified his claims about constitution embodiment. In older work (Noë, 2004) embodiment was "only" reflected in the nature of skill, understanding and knowledge. In more recent work he has added the idea of a somatic field.

The organic, somatic field of sensations (is that) that forms the ever-present background to our lived achievement of the environment's presence. (Noë, 2012, p. 12, my brackets) 
The somatic field is the set of all bodily abilities and states that presents the world in a particular way. In that it equals the conception of the body schema in Merleau-Ponty quite closely and the function it plays for constitution embodiment. Bower and Gallagher come to a similar conclusion about Noë's work.

An enactive account of perceptual presence integrates bodily factors into the perceptual event as an essential, constitutive ingredient. The body here is understood as what phenomenologists call the "lived body," which includes the related notion of a "body schema" and the full ensemble of bodily factors prenoetically governing conscious life ... (Bower \& Gallagher, 2013, p. 110)

RECS (Chemero, 2009; Rietveld \& Kiverstein, 2014) is another member of PEC that defends a version of constitution embodiment. A central term of RECS that exhibits the idea of constitution embodiment is that of an affordance. For proponents of RECS, we experience and understand not objects in the world, but affordances. An affordance itself is a relation between the embodied abilities of an agent and the agent's environment (Chemero, 2003). Accordingly, we always experience or understand something that is at least co-constituted by embodied abilities and thereby our embodiment.

Importantly, embodied abilities need to be understood in the context of affordances as structural features of the body that determine the structure of the world that an agent encounters. That is, embodied abilities must not be merely understood as an ability that belongs to a body - as the causal precondition of perceiving or understanding the world as it is. This becomes clear if we exemplify what an affordance is. For instance, if I perceive a chair affordance, I do not experience a chair as a chair because I have the perceptual ability to perceive chairs. Rather, I experience a relation between me and an object that affords me sitting, because I have a body that can sit in a particular environmental situation. In accord with these deliberations, Silberstein and Chemero (2015) defend a form of neutral monism which they also ascribe to Husserl, Heidegger and Merleau-Ponty, according to which the world is constituted by relations that are co-constitutively dependent on embodied human beings.

As we can see, various contemporary philosophical projects that are strongly inspired by phenomenological thought are committed to one form or another of constitution embodiment. Even though the particular conceptions vary quite widely, there is a commitment to the idea that the body is in some sense co-constitutive of the world as it is experience-able or understand-able. ${ }^{7}$ Despite this popularity of constitution embodiment, the idea itself is not

\footnotetext{
${ }^{7}$ It is important to point out that the philosophical positions of the authors that I discuss in this section differ significantly from each other (Clark, 2008a; Kiverstein \& Clark, 2009; Gallagher, 2011; Vörös, Froese, \& Riegler, 2016). For instance, Chemero (2009) self-identifies as an entity and phenomenological realist, Noë (2012) as an enactive direct realist and Silberstein and Chemero (2015) as neutral monists. Accordingly, it seems problematic to discuss all these authors as somehow similar to each other in a single section. Yet, it is the case, as this section shows that these authors have a similar conception of constitution or co-constitution and that they constantly refer to phenomenological authors (or even Kant) and their ideas to support their claims about constitution, while accepting strong, non-transcendental, realist claims at the same time. Accordingly, it makes sense to discuss these
} 
as well spelled out as we might want it to be. In the following I provide a detailed discussion of the work of Husserl, Merleau-Ponty and Heidegger on constitution embodiment to remedy this circumstance. This will not only provide PEC with a coherent and detailed conception of constitution embodiment, but it will also unveil major conceptual inconsistencies in the work of proponents of PEC on constitution embodiment that we can thereby remedy.

\subsection{Husserl and Merleau-Ponty on Embodied Spatiality}

Husserl and Merleau-Ponty both claim that the body, as the lived body (Leib) or phenomenological body - as an organizational structure of experience - is constitutive of the objects of our experience (Dingkonstitution) (Husserl, 1989; Merleau-Ponty, 2012). ${ }^{8}$

The qualities of a material thing as aestheta, such as they present themselves to me intuitively, prove to be dependent on my qualities, the make-up of the experiencing subject, and to be related to my Body and my "normal sensibility". (Husserl, 1989, p. 61, emphasis in original)

Similarly, Merleau-Ponty claims that "perceptual consciousness," which is dependent on the body schema, "constitutes its objects" (Merleau-Ponty, 2012, p. 28); that "my body is that by which there are objects" (Merleau-Ponty, 2012, p. 94), and that the body schema not only unites my senses, but also unites the objects of my perception (Merleau-Ponty, 2012, p. 244).

These are strong claims that suggest that the body plays a significant role in the constitution of how we experience and understand objects - or even in the constitution of objects themselves. In the following I discuss examples provided by Husserl and Merleau-Ponty to receive a better understanding of constitution embodiment.

Husserl discusses the role of the Leib for object constitution as an organ of perception (Wahrnehmungsorgan). In order to do so, he describes the dependence of perception on the body. For instance, touch is dependent on the hands, hearing on the ears.

The Body is, in the first place, the medium of all perception; it is the organ of perception and is necessarily involved in all perception. In seeing, the eyes are directed upon the seen and run over its edges, surfaces, etc. When it touches objects, the hand slides over them. Moving myself, I bring my ear closer in order to hear. (Husserl, 1989, p. 61; emphasis in original)

This characterization of constitution embodiment is admittedly weak. Husserl does not state more here than that the sense modalities that present us objects refer back to the body; for instance, touch to the hands. Obviously, Husserl presents this characterization of

\footnotetext{
authors in a single section as part of a singular movement, merely based on their similar conceptions of embodiment and constitution, since these ideas are the objects of this study. How these authors can reconcile to adhere to different species of realism and scientism while defending a form of constitution embodiment should be of concern to these authors and points directly towards the conceptual problems that I discuss in section 3 of this paper.

${ }^{8}$ I want to make clear that in the following I draw primarily on Husserl and Heidegger and that I discuss MerleauPonty's work mainly for the sake of a more complete account that also demonstrates Merleau-Ponty's commitment to a constitutive role of embodiment. Research that develops a more explicit and detailed conception of constitution embodiment among the lines delineated in this paper with a more detailed focus on Merleau-Ponty's work will have to await future research.
} 
constitution embodiment in the context of his general considerations about constitution, i.e., Husserl has already established object constitution as dependent on a subject as part of his transcendental-phenomenological project. This subject has been primarily characterized, resembling Kant, as a form of pure consciousness. Accordingly, with the considerations above Husserl seeks to introduce the idea that this constituting subject is embodied. Yet, the passage above does so only in the form of a trivial entailment of his transcendental project and does not provide a sufficient characterization of constitution embodiment on its own.

Similar concerns apply to other examples that Husserl provides to elucidate constitution embodiment. For instance, Husserl discusses how disturbances of and changes to the sense organs cause changes in the perception and appearance of objects. He describes how blisters on one's fingers cause changes in the perception of the textual structure of objects and how taking drugs or wearing colored glasses changes the perceived color properties of objects (Husserl, 1989, p. 66).

Again, these considerations only provide a case for constitution embodiment within the wider framework of Husserl's transcendental project. Without this context, these examples could be taken as descriptions of, for instance, breakdowns of the proper functioning of sense organs which create disturbed perceptions, rather than differently constituted objects. This means the examples of constitution embodiment that Husserl has provided so far could even be cited by proponents of body neutrality, if taken out of the context of Husserl's wider project.

Different from these weaker considerations is the following case. Husserl (1989, p. 56) presents the lived body and its role in object constitution as "the bearer of the zero point of orientation," or more mundanely expressed, as the necessary perspective on the world.

Furthermore, obviously connected with this is the distinction the Body acquires as the bearer of the zero point of orientation, the bearer of the here and the now, out of which the pure ego intuits space and the whole world of the senses. Thus, each thing that appears has eo ipso an orientation relation to the Body, and this refers not only to what actually appears but to each thing that is supposed to be able to appear. If I am imagining a centaur I cannot help but imagine it as in a certain orientation and a particular relation to my sense organs: it is "to the right" of me; it is "approaching" me or "moving away"; it is "revolving," turning toward or away from "me"-i.e., from my Body, from my eye, which is directed at it. (Husserl, 1989, pp. 61-62)

Similar points about the perspectival nature of perception, relative to our embodiment, can be found in Merleau-Ponty's work. Merleau-Ponty claims that the body is our "point of view on the world" (Merleau-Ponty, 2012, p. 73) and that the body functions as the "pivot of the world" (p. 84).

Even though not fully explicated, Husserl describes here a particularly strong condition of constitution embodiment. Like Kant and the transcendental tradition, Husserl argues that space is intuited: "the pure ego intuits space and the whole world of the senses" (Husserl, 
1989, p. 61). ${ }^{9}$ Importantly, space is not intuited as one thing among others; it has an excellent role as an invariant structure of experience, because, as Kant had already argued, it is the precondition of objecthood in the first place:

One can never represent (rather: imagine/vorstellen) that there is no space, although one can very well think that there are no objects to be encountered in it. It is therefore to be regarded as the condition of the possibility of appearances, not as a determination dependent on them, and is an a priori representation (rather: imagination/Vorstellung) that necessarily grounds outer appearances. ${ }^{10}$ (Kant, 1998, A24, B38; my brackets)

Each object that I can meaningfully conceive of - imagine - either in thought or experience, requires that I understand it as a spatial object.

Where Husserl seems to deviate from Kant is that the former argues that bodily perspective characterizes the spatiality of our experience. Accordingly, we do not experience the world in a disembodied space in which all parts are not differentiable from each other, as Kant argued (Kant, 1998, B40, A25). Rather, the spatiality of our experience is relative to me and my perspective; parts of space, or rather, places, are closer to me, others far away, and still others show up merely as a hardly differentiable horizon. In that sense, Husserl provides an important correction of Kant's disembodied conception of space.

Yet, it seems that we can draw an even stronger conclusion from Husserl's considerations. We can argue that the size of objects is experienced relative to our morphological embodiment. Objects appear as tall and small relative to my own size and effector space. In that sense, embodiment is, in a twofold sense, constitutive for space. First, it determines the spatiality of our ordinary, or as Heidegger would state, "everyday" conception of the spatiality in which we dwell. Second, the possibility of acting depends on this form of embodied spatiality. One important condition for the possibility of acting on objects is the size of objects relative to my body and relative to, for instance, the reach of my arms and grasp. Understanding the spatiality of objects as relative to my own embodiment is the condition that makes it possible to utilize objects for action. Similarly, Merleau-Ponty (2012, p. 140; emphasis mine) states: "to move toward an object, it needs to exist for the body." And an object exists only for the body, if the object reflects the abilities and properties of the body — bodily spatiality among them — so that the body can be receptive to the object.

\footnotetext{
${ }^{9}$ Thompson (2011) follows Kant and Husserl here- even though in an inconsistent way as we will see in section 3.2 - in that he claims that spatiality and temporality are created by the body. Noë (2004) also makes clear that embodied beings enact spatial content.

${ }^{10}$ Kant uses the German terms "Vorstellung machen" and "Vorstelleung" in the passage quoted here (Kant, 1956, A24, B38). To "vorstellen" or "Vorstellung machen" clearly means in German to imagine something (we can even literally translate it into "putting something in front (of me/us)" - and might be technically translated as "intuiting something." A "Vorstellung" is an imagination and might be technically translated as an "intuition." To translate these terms into "representation" and "represent" is the expression of an unwarranted rationalist re-interpretation of Kant's work that severs the clear connection between Kant's and Husserl's work shown above, which helps us to understand constitution embodiment more clearly as part of transcendental philosophy (Jeuk, 2017).
} 
If we interpret Husserl in this sense - that embodiment is co-constitutive of the spatiality of objects - we can gain even more insight from his work.

To the possibility of experience there pertains, however, the spontaneity of the courses of presenting acts of sensation, which are accompanied by a series of kinesthetic sensations and are dependent on them as motivated: given with the localization of the kinesthetic series in the relevant moving member of the Body is the fact that in all perception and perceptual exhibition (experience) the Body is involved as freely moved sense organ, as freely moved totality of sense organs, and hence there is also given the fact that, on this original foundation, all that is thingly-real in the surrounding world of the Ego has it relation to the Body. (Husserl, 1989, p. 61; emphasis in original)

Now it might seem at first glance that Husserl argues here for a position similar to the sensorimotor view of experience proposed by O'Regan and Noë (2002) and Noë (2004). This position states that the perceptual experience of objects is dependent on the movement and potential movability of our bodies. Take visual perception as an example. Our retina is at best receptive to information about a two-dimensional world. Yet, we experience a world in three dimensions. Accordingly, we need to account for what adds to perception so that we can perceive the world as we do. O'Regan and Noë argue that fullblown perception comes about if the perceiving agent utilizes her sensorimotor, bodily understanding. This understanding accounts for the possible movements that the agent could perform with regard to the objects of her perception, which entails an understanding of the possible perceptual vantage points that the agent could have with regard to the objects of perception. For instance, through my sensorimotor knowledge I understand how the backside of the tomato in front of me could look if I sensed it directly from a position opposite to mine. This perspectival understanding then allows for perceptual understanding of full-blown objects, rather than of an understanding of two-dimensional objects only.

As insightful as this account might be, it is only an account of the perception of objects. However, it does not account for the constitution of objects and accordingly falls short of constitution embodiment.

Yet, if we understand Husserl along the lines that I have suggested above- that our embodiment co-constitutes the spatiality of our experience-we can see how movement and movability are constitutive for the spatiality of objects. As I suggested above, the body of an agent determines the spatial properties of the objects surrounding her. Yet, these properties are not only determined by static factors, i.e., the particular size and morphological form of my body. Rather, movement, or my ability to move in particular ways, further specifies the spatiality of objects. Movement and movability add a dynamic factor to the morphological one. The spatial attributes of objects are dependent on the pace with which I can move relative to them. For instance, the apple in front of me is not only close, because I can reach it quickly, but it is also small, since I can walk around it in a matter of a "stride."

According to Husserl and Merleau-Ponty, embodiment constitutes the spatiality of objects in a two-fold sense. First, it determines their everyday appearance - the appearance that makes objects objects for us and that creates the familiarity that we have with them. An 
apple is partially an apple for me because it has the particular spatiality that it has in most cases in which I encounter it and that it can potentially take. Second, constitution embodiment is a condition for the possibility of action. If objects did not reflect the properties and abilities of the agent's body that acts with and on them, they would not be there for the body, as Merleau-Ponty argues.

As central and important as spatiality is for the constitution of objects, it is only one among various constitutive elements of objects. Importantly, the spatiality of objects primarily seems to have significance for us as far as it is relevant for action. Yet, action is not only not motivated by the spatiality of objects - I do not want to sit on a chair, because a chair has a particular spatial profile, even though this spatial profile allows me to sit in the first place. Rather, I am motivated to sit on a chair, if I have concern to do so. But, action further requires concern so that we experience and understand things as things for action, i.e., concern is the condition of the possibility that things show up as things that matter to us. Importantly, this concern is of an embodied nature. In the following I present Heidegger's considerations on concern ("care") and show how they lend themselves to a comprehensive version of constitution embodiment in connection with the deliberations of Husserl and Merleau-Ponty discussed above.

\subsection{Heidegger on Care}

That Heidegger has not explicitly written about the body, with a few exceptions (Heidegger, 1962, p. 368, 2001), is "well-known" (Guignon, 2009; Zahavi \& Overgaard, 2012). Yet, we should not confuse Heidegger's silence on the morphological, let alone biological body, with silence on the body itself (Overgaard, 2004, 2005). Despite generally circumventing the word "body," Heidegger provided a particularly sophisticated idea of what I denote with the term "constitution embodiment." What is of particular relevance here is Heidegger's idea of care (Sorge), or, as I will call it in the following, "concern."

Heidegger argues in Being and Time that concern is the being of Dasein, the ontologically basic way of being-in-the-world (Heidegger, 1962, p. 329, bracket mine): "Dasein's being is care (concern)." This means that concern is a condition of the possibility of being-inthe-world. Differently put, concern is an invariant structure of our experience and understanding. Concern itself has the following four structural components (Strukturmomente): Affect, understanding, falling and discourse (Heidegger, 1962, p. 335). ${ }^{11}$ In the following I will focus on affect to show how concern provides us with a convincing conception of constitution embodiment.

\footnotetext{
${ }^{11}$ Affect is my translation of the German term "Befindlichkeit" (Heidegger, 2006). It is also translated with "state-of-mind," such as in the standard English translation by Macquarrie and Robinson (Heidegger, 1962), or with "affectedness" (Dreyfus, 1991).
} 
The considerations by Husserl and Merleau-Ponty that I have discussed above provide a conception of constitution embodiment that suggests that our embodiment determines the spatiality of objects. But as such, objects are not sufficiently individuated. The objects that surround us are not just points in space-time. Neither are they merely persistent (beharrlich) substances, as Kant argued. Rather, objects have significance to an agent that enacts them.

This is quite obvious when we think about artifacts, such as a car. ${ }^{12} \mathrm{~A}$ car ordinarily appears as a car, in that it affords fast, safe and comfortable travelling from point A to B. Being fast, safe and comfortable are properties of cars that are co-constituted by our embodiment. A car is fast compared to how swift we can move. A car is safe compared to the physical robustness of our bodies. And a car is comfortable, given that embodied beings such as us sense sitting in cushioned seats in a particular way. Yet, importantly, these properties show up, because we have, as Heidegger would state, concern for time-efficiency, safety and comfort —in particular, these things have affective appeal to us.

If my concern structure had no place for time-efficient travel, say, if I were an immortal being that does not have to care about time, a car would accordingly not show up as a fast means of travel, even if it were objectively "faster" than me walking from place A to B. Importantly, we are not immortal beings, or beings that are so robust that they do not have to care about safety. Also, we are such beings because we have a particular embodiment. We are mortal and vulnerable. Even more importantly, we are not only such beings, but we care for our survival and goals, since we are beings with embodied interests, i.e., we have affect. I fear death and accordingly want to travel safely. I feel joy if I make "a sale" and accordingly need to be on time for the meeting. I appreciate comfort and dislike the strain in my legs from long walks. Given these very embodied concerns, things show up in a certain way for me. A car as safe. A bed as comfortable. A computer as a time-efficient means of working.

One might reply that this is the case for artifacts, but is this also the case for non-artifacts? Heidegger's answer to this is clear.

Here, however, "Nature" is not to be understood as that which is just present-at-hand, nor as the power of Nature. The wood is a forest of timber, the mountain a quarry of rock; the river is water-power, the wind is wind "in the sails". (Heidegger, 1962, p. 100; emphasis in original)

Let us imagine walking along a forest path in the woods. If I am not a dedicated lumberjack, I will not primarily conceive of the trees around me as commercial forest-pace Heidegger's example. Rather, trees might appear as objects of contemplation and might be part of my concern for recreation in nature. Alternatively, I might conceive of them as

\footnotetext{
${ }^{12}$ The phenomenological or transcendental method does not provide definitions of entities, but establishes the conditions of the possibility of these entities. Before we discuss the example of how our experience and understanding of cars is co-constituted by concern, it is important to keep in mind that concerns vary from person to person and are not only based on a person's embodiment, but also on a history of individual and social interactions with one's world. Therefore, the following does not attempt to give a definition of a kind (of car), but to exemplify how one possible way among many ways in which concern as a condition of the possibility of understanding cars might present cars to a person.
} 
obstacles that hinder me from moving comfortably and safely. For instance, if I leave the path I might fall over the tree roots that cover the forest floor and I might break my leg or cut myself on branches.

That I can cut myself is relative to the particular density of the branches relative to my skin and movement. My skin is vulnerable, because it can be cut quite easily by something mundane like a tree branch and the tree branch is sharp and dense because a creature with my skin and my movement speed will cut herself with the branches. Importantly, among all the possible relations that hold between me and trees, these things show up because they are significant. They are significant to me, because my body can easily get hurt relative to this forest structure. But what ultimately grounds this significance is not my morphological or biological body, but the circumstance that I have affective concern for not hurting myself and for averting pain. Accordingly, the same considerations that apply with regard to constitution embodiment towards artifacts also apply to non-artifacts.

Here we can clearly see how Heidegger provides a conception of constitution embodiment. Affect is embodied and affect underlies concerns. Thereby, concerns are not mere concerns, but concerns of embodied beings, immersed in a world of objects that matter to them.

\section{Conceptual Problems with PEC's Use of "Constitution Embodiment"}

I have focused in my analysis of constitution embodiment on two factors: how the body constitutes the spatiality of objects and how the body renders objects as significant in the first place. In the following I will analyze how PEC's conceptions of constitution embodiment fare with regard to these considerations. I will show that PEC's versions of constitution embodiment are conceptually inconsistent in that they confuse constitution embodiment (a transcendental claim) with a positive claim. I will further show that the focus of PEC on the location of the body is an entailment of this conceptual inconsistency that yields unproductive philosophical and scientific debates and research alliances.

\subsection{Constitution Embodiment Is a Transcendental Claim - Not a Scientific Claim}

Constitution embodiment is what Heidegger calls an "ontological" claim-a claim about structures that determine the possible ways the world can appear to us and how we can understand it. Differently put, constitution embodiment is a transcendental claim that makes explicit the existential conditions - in this case, bodily conditions - that are the possibility of experience and understanding. As we have seen above, the body co-constitutes the spatiality and significance of objects that we understand and experience. As such, constitution embodiment is a genuinely philosophical claim that is established by means of the phenomenological method. Importantly, constitution embodiment cannot be established or formulated as a claim that "explain(s) Reality ontically by Real connections of interaction between things that are Real" (Heidegger, 1962, p. 251), i.e., "Being cannot be explained through entities" (Heidegger, 1962, p. 251). 
Unfortunately, many approaches by proponents of PEC defend a version of constitution embodiment that does not treat the body as a constitutive condition that gives us entities, but as a physical thing among others, i.e., as an entity. Take for instance Enactivism. The bacterium as well as the world of sugar that it inhabits (see the example in section 2.1) is treated exactly as what Thompson (2007, p. 13) has called a "prespecified world." A world that can be accounted for by providing a description of how the organism is physically, chemically and biologically coupled to its environment - a world that can be "explain(ed) by Real connections of interaction between things that are Real" (Heidegger, 1962, p. 251). Differently put, Thompson and Stapleton treat sugar as a prespecified given that can be represented in different ways; for instance as food, instead of as something that is itself constituted or "enacted" by the body.

This obviously entails an inconsistency. It is analytically impossible to argue for constitution embodiment from a perspective that is different from our own, since constitution embodiment states that an embodied agent constitutes her own world. Accordingly, we can only describe the world from our own perspective by describing it as reflective of our embodiment. ${ }^{13}$ Importantly, this is a phenomenological task, not a scientific one that describes the body as a physical given — as coupled to a pre-given world. ${ }^{14}$

A similar criticism applies to RECS. If affordances are co-constituted by our embodiment, if doing science is itself dependent on embodied abilities (Rietveld \& Kiverstein, 2014), and if we encounter the world by experiencing affordances, then we cannot treat the body as a physical thing that is located in a world that is not itself co-constituted by our own embodiment. But this is exactly what RECS does when it treats claims about affordances and the relationship between agents and their environment as scientific claims that can be primarily explained by means of dynamic systems theory and the explanatory apparatus of ecological psychology (Chemero, 2009; Favela \& Chemero, 2016). The body is treated here as an entity, not as a condition of the constitution of entities.

Like Enactivism, RECS commits the fallacy of understanding the Leib not as a constitutive condition of understanding and experience, but as a real, physical thing that is placed inside the world that it is supposed to co-constitute. Like Enactivism, RECS confuses an ontological or transcendental claim with a positive or ontic claim.

This is not only inconsistent, but it also leads to the problem that Enactivism and RECS risk, i.e., that their claims receive uncharitable re-interpretations. For instance, Enactivism

\footnotetext{
${ }^{13}$ If Thompson and Stapleton claimed that the way we conceive of the Umwelt of the bacterium is co-constituted by our embodiment and that this Umwelt is the object of a biological study - and not part of a phenomenological study that extends to a phenomenological study of the human world - then their claim would be correct and highly interesting. However, in the form in which their claim is presented now, it runs into conceptual inconsistency, as I demonstrate in this section.

${ }^{14}$ Similar considerations apply to Noë's work. Noë (2005) explicitly asks for an intermeshing of science and philosophical method and a rejection of pure conceptual analysis. Noë (2007) does the same, only with regard to phenomenological analysis rather than conceptual analysis. Here, as in the case of Thompson, the problem emerges that the boundaries between ontological or transcendental and positive or empirical claims vanish.
} 
can, in its current form, be consistently reduced to selective representationalism (Mandik \& Clark, 2002), which claims that we merely selectively represent features of a prespecified world that are important for action. And RECS is at the risk that affordance theory is reduced to the idea that affordances are functional predicates for action, not unlike the post-hoc value predicates criticized by Heidegger (1962) and Dreyfus (2007). Obviously, this is not in accord with the phenomenological foundations of Enactivism; neither is it consistent with the phenomenological and neutral monist foundations of RECS that clearly attribute an ontological role to affordances and our experience of them (Chemero, 2009; Silberstein \& Chemero, 2015).

Here we see clearly that PEC might not be as clear about the relationship that is supposed to hold between phenomenology, or philosophical method in general, and scientific research, as the plethora of literature on the topic otherwise seems to suggest. ${ }^{15}$ If, for instance, the body is treated undifferentiatedly as a condition of the constitution of entities and as an entity, then conceptual inconsistency is entailed.

Obviously - dependent on the context of research - we can treat the body as a condition of the constitution of entities and as an entity. For instance, if we research into the nature of positive psychological phenomena such as concrete movement or problem solving, we have to treat the body as an entity. But if we deal with ontological phenomena, we need to treat the body as a condition of the constitution of entities, and not as an entity.

\subsection{Problems with Claims about the Location of the Embodied Mind}

A conceptual entailment of the conceptual inconsistency demonstrated above is how the body is treated by proponents of PEC in relation to space. The body is treated as an entity located in space. Indeed, it seems as if claims about the location of the "embodied mind" are the major argumentative domain of PEC. The basic claim is that the embodied mind is not in the brain or body alone, but that it is in the world (Wheeler, 2005; Rowlands, 2010; Gallagher, 2015), "out of our heads" (Noë, 2009), spanning the entire animal-environment system (Favela \& Chemero, 2016), or that it is an extended phenomenological-cognitive system (Silberstein \& Chemero, 2012). The embodied mind cannot be a brain in a vat but requires its environment (Thompson \& Cosmelli, 2011), and - so the arguments go - the embodied agent is constantly coupled to its environment (Thompson, 2007; Chemero, 2009).

But, as we have seen in section 2.2, the body itself is a constitutive condition of the possibility of how things show up to me in space. As Heidegger states:

Dasein is essentially not a Being-present-at-hand; and its "spatiality" cannot signify anything like occurrence at a position in "world-space", nor can it signify Being-ready-to-hand at some place. Both of these are kinds of Being which belong to entities encountered within-the-world. Dasein, however, is "in" the world in the sense that it deals with entities encountered withinthe-world, and does so concernfully and with familiarity. (Heidegger, 1962, p. 138)

\footnotetext{
${ }^{15}$ See the literature referred to in the introduction.
} 
If that is the case, the body, at least as conceived of according to constitution embodiment - as an ontological individuation condition - cannot be located in space itself, because the way we conceive of space is itself constitutively dependent on the body. As Merleau-Ponty (2012, p. 40) makes clear, "the thing is in place, but perception is nowhere, for if it were situated it could not make other things exist for itself, since it would remain in itself in the manner of things." 16

Constitution embodiment is not an entity itself, but a condition of the constitution of entities, and can therefore not be located anywhere. ${ }^{17}$ To repeat this point; it is clear that there are interesting psychological and biological claims about positive phenomena such as intelligence, motor control or problem solving which pertain to the location and potential extendedness of these phenomena. However, we need to clearly pry apart what pertains to this positive, psychological project and what pertains to the ontological project surrounding constitution embodiment. And PEC is at the very least not clear about making the distinction between the body as a condition of the constitution of entities and the body as an entity that is the subject of psychological processes that might or might not extend into the environment. ${ }^{18}$ We can see this in Silberstein's and Chemero's work on neutral monism and the temporality of experience.

The experience of time, for example, is neither in the head (the subject) nor the external world (the object), the experience is fundamentally relational or extended. It is the self-consistency relation between subject and object that allows for the experience of time. This relation or structure is not in anything nor located anywhere. (Silberstein \& Chemero, 2015, p. 192; emphasis mine)

Silberstein and Chemero state correctly - following the phenomenological tradition - that the experience of time, or perhaps rather the temporality of experience, has no location.

\footnotetext{
${ }^{16}$ My point here is obviously not to claim that the we should accept brain or body internalism about the embodied mind. Rather, my point is that we should not make claims about the location of the embodied mind in the first place.

${ }^{17}$ It is not entirely clear that Husserl (1989) and Merleau-Ponty (2012) would agree with me on this point. See for example their treatment of double sensation. The idea, in a nutshell, is that our bodies are themselves coconstituted by our engagement with the objects of our experience. In that sense, our bodies, as lived bodies, are locatable relative to the objects that contribute to their co-constitution. I leave it open here whether the object of double sensation is the lived body, or our body as experienced by ourselves that is locatable relative to objects with which we engage, and, accordingly, whether the body as a principle of the constitution of entities can actually be located or not. Be that as it may, it is important to point out that my claim still stands that the body as a principle of the constitution of entities is not locatable in physical space but only - if it is locatable at all -in perspectivally experienced space. i.e., as the object of phenomenology and not of science.

${ }^{18}$ For a similar point, please see Vörös and Gaitsch (2016). Both authors argue that much of embodied cognition merely extends the study of the mind to the body and environment without a substantial and critical conceptual and ontological overhaul, a process that they call "bodification" (Vörös \& Gaitsch, 2016, p. 17). As they claim: "Thus, instead of looking for ways that would enable us to implement a radically different attitude towards the (study of) conscious mind, so that we may begin to unearth the flesh-and-blood texture of embodied experience, such accounts settle for more anemic conceptions in which paying heed to the body more or less means extending the abstract explanatory substratum that has been at work in classical cognitive science. The bodified mind is thus a pale cousin of the embodied mind" (Vörös \& Gaitsch, 2016, p. 18). I agree.
} 
At the same time, though, they claim that the structure that is the condition of the possibility of the temporality of experience is extended. But, as soon as something is extended, as Descartes (1986) already made clear, something is taking place in space and has thereby a location. And this then, again, leads to conceptual inconsistency. ${ }^{19}$

\subsection{Problems with Treating Affect as a Psychological Phenomenon}

As Heidegger (1962) argued - see section 2.3-objects that I encounter in the world are not spatiotemporal objects, nor substances with properties. They are first and foremost things that matter to me. Yet, objects do not matter to me based on their physical properties. Objects, as I experience and understand them, matter to me because they are co-constituted by concern; importantly, by affect. ${ }^{20}$

This Heideggerian insight has been widely ignored by most proponents of PEC - with the laudable exception of the so called "autopoietic" branch of Enactivism (Thompson, 2007; Thompson \& Stapleton, 2009). Independent of the inconsistency that I have demonstrated in section 3.1, Thompson and Stapleton (2009) go at least in the right direction when they claim that, for instance, sugar shows up for the bacterium as sugar-as-food because it has significance for the organism. Unfortunately, Thompson and Stapleton treat this significance as the result of chemical coupling, but other work by Thompson $(2007 ; 2011)$ suggests that he correctly identifies this generation of significance with purpose, which he grounds in affect. Again, this insight is tainted, since affect is treated by Thompson as a positive phenomenon, which entails that affect plays merely a selective representational role in the generation of significance. But, if PEC becomes clear about the treatment of affect as a constitutive phenomenon that pertains to constitution embodiment, this problem can be circumvented.

Enactivists, and with them all proponents of PEC, need to be clear about whether they treat affect transcendentally or psychologically. ${ }^{21}$ Only a psychological conception of affect is also a biological phenomenon that is locatable in the "inner body" (Colombetti \&

\footnotetext{
${ }^{19}$ We encounter a similar mistake in the literature quite often. On the one hand, "localism" (de Oliveira \& Chemero, 2015) or the "the spatial containment language of internal/external or inside/outside" (Thompson \& Stapleton, 2009, p. 26) are correctly criticized. But then on the other hand, Oliveira and Chemero argue for extended cognition based on empirical evidence, and Thompson and Stapleton provide an account of the embodied mind as a neurological system that is continuously coupled to its environment; i.e., they defend claims about the extendedness of what they identify with the physical realization basis of the embodied mind. Yet, as I have pointed out, if something is extended, it is localizable in space.

${ }^{20}$ See section 2.3 .

${ }^{21}$ One might reply to me here that the same demands that I make on proponents of PEC could also be made on Merleau-Ponty, who constantly blurs the distinction between the psychological and the transcendental. Indeed, I am afraid the same demand should be made on Merleau-Ponty. Proponents of PEC cannot simply follow Merleau-Ponty because he is Merleau-Ponty. They rather have to show how Merleau-Ponty was conceptually justified in blurring the boundary, either by reconstructing the conceptual argument that Merleau-Ponty gave (if there is any such) and by demonstrating that it is conceptually consistent, or by proving a conceptual argument of their own that applies at least to their work and would justify how they can blur the boundary between the transcendental and the psychological.
} 
Thompson, 2008; Kiverstein, 2012; Stapleton, 2013; Colombetti, 2014; Kiverstein \& Miller, 2015). Only a psychological conception of affect determines the effort that is necessary to perform an action (Bower \& Gallagher, 2013). Only a psychological conception of affect pertains to direct relevance detection, motivation or the guidance of attention (Stapleton, 2013; Colombetti, 2014; Kiverstein \& Miller, 2015). All these aspects of affect are psychological, and in a certain sense, trivially embodied. They have to be clearly differentiated from a conception of affect that pertains to constitution embodiment - a conception of affect that co-individuates the objects that we can possibly experience and understand.

To be sure, a proper conception of constitution embodiment might entail an account of the psychological phenomena named above. Since objects are co-constituted through concern, they have, for instance, intrinsically motivational power and solicit options for action that show up as relevant in a context. Yet, if we make use of a transcendental conception of affect for the explanation of psychological phenomena, we still need to be clear about what of the explanation of these phenomena requires a transcendental investigation that is about the invariant structures that constitute entities, and which part of the investigation pertains to a positive, psychological project, that is, about "variant" structures of experience that vary from person to person and from culture to culture (Sartre, 1962).

\subsection{Philosophical and Practical Consequences of these Inconsistencies}

So far, my criticism has primarily focused on conceptual inconsistencies. But, there is also a different way to highlight what is problematic about confusing embodiment as a constitutive, ontological condition of entities with claims about psychological and biological entities. The problem is that claims about the physical location of the embodied mind-in the context of constitution - are usually conceptually empty. To be sure, they are conceptually empty because they are based on the conceptual mistakes pointed out above. But phrasing it this way makes it more apparent what is problematic about these conceptual inconsistencies.

Now, it is obviously difficult to show in concreto how claims like these are conceptually empty. Yet, I think the following deliberations support my claim. Various philosophers, among them proponents of PEC, but also proponents of the Extended Mind (Clark, 2008b), Radical Enactivists (Hutto \& Myin, 2013) and semantic externalists (Putnam, 1975) all claim that the (embodied) mind spreads into the world or part of the world. This should already give us pause, given the different conceptions of the mind to which these authors adhere. Take, for instance, the cases of Thompson on the one hand and Hutto and Myin on the other hand. Thompson is a phenomenologist, whereas Hutto and Myin come close to being modern-day behaviorists. ${ }^{22}$ Yet, both claim that the embodied organism is

\footnotetext{
${ }^{22}$ Hutto and Myin further accept the idea that content exists and try to explain it, partly, with a Wittgensteinian account. I leave it open here to the reader whether she can make the case that it is possible to reconcile phenomenology with a quasi-behaviorist account that is coupled with a semanticist reading of Wittgenstein, teleosemantics and a potpourri of other non-phenomenological accounts, including Davidsonian interpretationalism (van
} 
constantly dynamically coupled to its environment and that the embodied mind spans the organism and the environment to which it is coupled. ${ }^{23}$

It seems that if such claims about the location of the embodied mind were meaningful, i.e., not empty, that there were conceptual entailments that would either derive or at least suggest, for instance, a phenomenological or a quasi-behaviorist account of the mind. But, it seems that there are no such entailments or criteria. Instead, both claims about the location of the mind and claims about the specific nature of the mind seem to stand in no relationship whatsoever; this is dubious if claims about the location of the mind should be meaningful. The same does not hold for constitution embodiment proper. For instance, constitution embodiment determines the significance of objects as deriving from the spatiality and concern structure of an agent, which is at odds with an account like Hutto's and Myin's.

In a similar fashion, and connected to the point above, is a pragmatic concern about proper scientific and philosophical alliances among research projects, which also underlines the problems with the conceptual inconsistencies pointed out earlier. We find constantly strong opposition between externalists and internalists about the embodied mind. For instance, Anderson and Chemero (2013) criticize Clark's (2013) brain-based account of predictive coding as "threaten(ing) to return us to the bad old days of epistemic internalism" (Anderson \& Chemero, 2013, p. 24). Similarly, Gallagher (2015, p. 99) criticizes proponents of grounded cognition such as Barsalou, Gallese, Johnson, and Lakoff for being "internalists" and thereby close to "classic cognitivism." At the same time, for instance, Hutto and Myin (2013) are seen as part of either Enactivism or RECS (Chemero, 2009) because they are externalists about the embodied mind.

What is concerning about this is that these research alliances are based on-at least with regard to constitution and specification - inconsistent and empty claims such as that about the location of the embodied mind. For instance, it seems dubious that Hutto and Myin's "Radical Enactivism" belongs to the same research project as Chemero's or Thompson's work. While Hutto and Myin claim that animals have no meaningful thought because they lack language, phenomenologists claim that meaningful thought arises from more basic structures, like concern. Further, language, as that which constitutes meaningful thought for Hutto and Myin, is understood by them in a disembodied, classic sense, according to which the world can, at least in principle, be mirrored as it is. This means that Hutto and

den Herik, 2014). In any case, it would be desirable to see an in-depth study that shows the conceptual coherence between those accounts amid the current trend that stresses more general similarities between, for instance, Heidegger's and Wittgenstein's work (Braver, 2012).

\footnotetext{
${ }^{23}$ The coupling terminology shows us another problem with the interaction between phenomenology and a scientific approach. Thompson claims that "an autonomous system is always structurally coupled to its environment. Two or more systems are coupled when the conduct of each is a function of the conduct of the other" (Thompson, 2007 , p. 45). Yet, this is a causal connection between entities. Contrary to that, Heidegger (1962) and other proponents of a classic conception of constitution embodiment argued that the objects of our experience and understanding are always objects of our world and that our world always reflects our (constitutive) embodiment. Here we see how a causal relationship, coupling, is confused with an intentional and co-constitutive relationship.
} 
Myin are close to the classic conception of body neutrality towards which constitution embodiment is radically opposed. Not surprisingly, they mock Enactivist claims - claims at the heart of constitution embodiment - about how embodied beings enact their world as “extravagant claims" (Hutto \& Myin, 2013, p. 5).

At the same time, researchers that are committed to the idea that the experience and understanding of the world reflect our embodiment — such as Lakoff and Johnson (1999) and Gallese and Lakoff (2005) — are criticized for being classic cognitivists. Other researchers (Berthoz \& Christen, 2009) that make strong claims about how our experience and understanding of the world are reflective of our embodiment are widely ignored by proponents of PEC because they focus in their research on the brain. Importantly, these researchers make the same mistake as the proponents of PEC; they treat embodiment as a condition of the constitution of entities and as an entity. Accordingly, their internalism needs to be revoked. But, the focus on constitution and specification in their work itself can be maintained and used for fruitful research alliances. ${ }^{24}$

Obviously, there are strong differences in the projects of "externalists" and "internalists" when it comes to their research of psychological phenomena. In this sense it is sensible to stress the divide between these different frameworks. Yet, from a philosophical, ontological point of view it seems that the commonality researchers express towards how the body constitutes or at least specifies the objects of our experience and understanding is significantly more important than the commonality that is based on conceptually empty claims about the location of the embodied mind. Constitution embodiment is basically a rejection of the natural attitude, in particular of body neutrality. Yet, if we focus on the alleged location of the embodied mind, we not only overlook this circumstance, but run into the danger that we accept positions that are clearly expressions of the natural attitude, such as Hutto's and Myin's linguistic conception of thought.

Another example of the infelicitous consequences of focusing on location is PEC's relationship to the father of Rationalism, Descartes. Cartesianism is the argumentative "opponent" of many proponents of PEC (Wheeler, 2005; Rowlands, 2010; Gallagher \& Zahavi, 2012). The major reason for this hostility towards Cartesianism is the belief that Descartes is the founder of internalism. Yet, contrary to this popular belief, Descartes (1986) made clear that the mind, as a res cogitans, is the opposite of a res extensa-a thing with extension-which entails by definition that the mind has no place or location in space. It is true that Descartes claimed that the pineal gland, as part of the brain, is the locus of mind-body interactions. But, since Descartes did obviously not assert that the mind is in any form reducible to the pineal gland or other physical entities, this should be taken more as a speculative and probably rather incoherent claim of Cartesian philosophy than as something that needs to concern proponents of PEC any further.

\footnotetext{
${ }^{24}$ See Jeuk (2017) for an account of embodied and conceptual understanding that is not committed to location and that is demonstrating how understanding is grounded in embodied schemata.
} 
Descartes' (1986) claim that we can imagine ourselves without a physical body is not problematic for proponents of constitution embodiment either, as long as we do not draw negative ontological conclusions from it, as Descartes did, pace Gallagher and Zahavi (2012). ${ }^{25}$ From a merely descriptive point of view it seems that we can imagine ourselves without a physical body - and, for the sake of the argument we can concede to Descartes that this is possible - again, as long as we do not draw, like Descartes, a negative ontological inference from it. Importantly, the objects that I imagine when I imagine that I do not possess a physical body are still constituted by constitution embodiment and therefore reflective of constitution embodiment. If I withdraw meditatively from the world and my body and imagine a car, then this imagined car still exhibits those properties that are constituted by my embodiment - being a safe means of travel that has particular spatial properties that refer back to my size and pace. That Descartes would have accepted this claim is unlikely. However, it still shows that Descartes' thought experiment is in itself not problematic. More importantly, Descartes' thought experiment clearly shows that it is not the physical body that matters for constitution embodiment, but the body as a condition of the constitution of entities. ${ }^{26}$

The problem with Descartes's Rationalism is not internalism or the idea that we can imagine ourselves without a physical body. Rather, the problem with Descartes and the Rationalist tradition - as Dreyfus and Taylor (2015) point out correctly and as Husserl and Heidegger did before them - is that they conceive of the world as independent of us and our embodiment. ${ }^{27}$ This means that Rationalism supports body neutrality and thereby the opposite of constitution embodiment. Exactly this aspect of Rationalism is not only overlooked due to the infelicitous focus on location, but it is even accepted by various proponents of PEC, that focus on location, but leave Rationalist conceptions of representation and thought untouched (Jeuk, 2017).

\footnotetext{
${ }^{25}$ To be clear, I do not defend Descartes' conception of mind here. I merely show that his thought experiment (that we can imagine ourselves without our body) can actually be consistently used to defend the idea of embodiment as a constitutive principle.

${ }^{26}$ The case is different for "brain in a vat" thought experiments, such as criticized by Thompson and Cosmelli (2011), which are commonly seen as an extension of Descartes' thought experiment. Wheras Descartes' thought experiment departs from a descriptive analysis of an experiential episode that we can have, a brain in a vat thought experiment starts from the very beginning with an ontological assumption or statement - that brains in vats could realize or are identical to the mind (or not) — but does not include any experiential analysis whatsoever. Wheras Descartes' thought experiment is partially epistemically dependent on an analysis of an experiential episode, a brain in a vat thought experiment is merely justified by an intuition about whether internalism or externalism about semantic content is the case. Therefore, my partial defense of Descartes' 'thought experiment,' or rather, of his phenomenological analysis, does not apply to brain in a vat thought experiments because I merely defend Descartes' experiential analysis that we can have experiential episodes that do not include direct awareness of our physical body. I do not defend Descartes' negative ontological conclusion that he draws from his experiential analysis. This conclusion is not a direct result of his experiential analysis, but depends further on his epistemology and the resultant idea that whatever we can imagine clearly and distinctly is also of ontological import.
}

${ }^{27}$ Varela et al. (1991) are also clear about this. Their famous term "Cartesian Anxiety" refers to the epistemic aspects of Cartesian philosophy, not to the ontological ones; let alone to those that pertain to the location of the mind. 
Constitution embodiment allows us to overcome body neutrality and with it the "Intellectualism" (Noë, 2012) and "Rationalism" (Dreyfus, 1971, 1988, 2007) at the heart of contemporary Analytic Philosophy and cognitive science. Instead of focusing on futile debates about the location of the embodied mind - at least when it comes to constitutionwe should make use of fruitful alliances between theoretical frameworks that emphasize the constitutive role of the body for experience and understanding.

\section{Conclusion}

Based on the work of Husserl, Heidegger and Merleau-Ponty, I have spelled out a consistent and sufficiently complex conception of constitution embodiment that can inform further philosophical research into the nature of constitution in general and into how the body constitutes objects of experience and understanding in particular. I have further shown how PEC fails to use the concept of constitution embodiment consistently; in particular, PEC confuses a transcendental claim about the constitution of entities through the body with a claim about the body as an entity. As I have demonstrated, this is not a harmless inconsistency that can be easily removed, but a deeper-rooted problem that will require PEC to be more specific about the boundaries between philosophy and science. Further, PEC will be forced to move its research focus from the location of the body to how the body constitutes and specifies the objects of experience and understanding. PEC will also have to consider with which research projects it will have to work in the future. I have suggested that PEC should engage into research alliances with other projects that focus on constitution and specification, rather than on the location of the embodied mind.

An obvious problem is that PEC seems to be torn apart between being a psychological project that investigates the nature of positive phenomena, such as problem solving, and being a philosophical project that provides an ontological analysis of the structure of the world. Whereas the former project might rightfully focus on the extendedness of, say problem solving - or at least on how problem-solving abilities require structures that are not only located in mechanisms in an organism's brain - the latter project will have to cede its claims about the location of the embodied mind altogether. PEC has to be very clear about which project it is concerned with and which particular conception of embodiment it accordingly has to use, depending on the respective research context with which it engages. Accordingly, PEC has to be clearer about the relationship between philosophy and science.

I hope my deliberations provide further insight into the truly "revolutionary" or "radical" potential of PEC. Instead of confining itself to claims about the realization-base of the embodied mind, in which PEC incoherently follows research questions defined by the metaphysical presuppositions of Analytic Philosophy and classic cognitive science that themselves derive from Rationalist philosophy (Dreyfus, 1971; Dreyfus, 1988; Varela et al., 1991; Dreyfus, 2007; Dreyfus \& Taylor, 2015; Jeuk, 2017), PEC should embrace the opportunity to see itself as a successor of the Phenomenological tradition, as Thompson (2007) and Noë (2012) already seem to suggest. As such, PEC should form a research 
program with which it can establish itself as a clear competitor to the Rationalist agenda, that defends the natural attitude and body neutrality, which still guides wide sectors of contemporary philosophy and cognitive science. Clearly, constitution embodiment should be at the forefront of this research program.

\section{References}

Alsmith, A. J. T., \& de Vignemont, F. (2012). Embodying the mind and representing the body. Review of Philosophy and Psychology, 3(1), 1-13.

Anderson, M. L., \& Chemero, T. (2013). The problem with brain GUTs: Conflation of different senses of "prediction" threatens metaphysical disaster. Behavioral and Brain Sciences, 36(03), 204-205.

Barsalou, L. W. (1999). Perceptual symbol systems. Behavioral and Brain Sciences, 22(04), 637-660.

Barsalou, L. W. (2008). Grounded cognition. Annual Review of Psychology, 59, 617-645.

Berthoz, A., \& Christen, Y. (2009). Neurobiology of "Umwelt": How living beings perceive the world. Berlin, Germany: Springer Verlag.

Boroditsky, L., \& Ramscar, M. (2002). The roles of body and mind in abstract thought. Psychological Science, 13(2), 185-189.

Bower, M., \& Gallagher, S. (2013). Bodily affects as prenoetic elements in enactive perception. Phenomenology and Mind, 4(1), 78-93.

Braver, L. (2012). Groundless grounds: A study of Wittgenstein and Heidegger. Cambridge, MA: MIT Press.

Carel, H., \& Meacham, D. (2013). Phenomenology and naturalism: Editors' introduction. Royal Institute of Philosophy Supplement, 72, 1-21.

Chemero, A. (2003). An outline of a theory of affordances. Ecological psychology, 15(2), 181-195.

Chemero, A. (2009). Radical embodied cognitive science. Cambridge, MA: MIT Press.

Clark, A. (2008a). Pressing the flesh: A tension in the study of the embodied, embedded mind? Philosophy and phenomenological research, 76(1), 37-59.

Clark, A. (2008b). Supersizing the mind: Embodiment, action, and cognitive extension. Oxford, UK: Oxford University Press.

Clark, A. (2013). Whatever next? Predictive brains, situated agents, and the future of cognitive science. Behavioral and Brain Sciences, 36(03), 181-204.

Colombetti, G. (2014). The feeling body: Affective science meets the enactive mind. Cambridge, MA: MIT Press. 
Colombetti, G., \& Thompson, E. (2008). The feeling body: Towards an enactive approach to emotion. In W. F. Overton, U. Müller, J. L. Newman (Eds.), Developmental perspectives on embodiment and consciousness (pp. 45-68). New York, NY: Lawrence Erlbaum Associates.

Descartes, R. (1986). Meditationes de prima philosophia: In qua Dei existentia et animae immortalitas demonstrator. Trans. as Meditations on first philosophy. In J. Cottingham, R. Stoothoff, \& D. Murdoch (Trans. and Eds.), The philosophical writings of Descartes. Volume II. Cambridge, UK: Cambridge University Press.

Dreyfus, H. L. (1972). What computers still can't do: A critique of artificial reason. Cambridge, MA: MIT Press.

Dreyfus, H. L. (1988). The Socratic and Platonic basis of cognitivism. AI \& Society, 2(2), 99-112.

Dreyfus, H. L. (1991). Being-in-the-world: A commentary on Heidegger's Being and Time, Division I. Cambridge, MA: MIT Press.

Dreyfus, H. L. (2007). Why Heideggerian AI failed and how fixing it would require making it more Heideggerian. Philosophical Psychology, 20(2), 247-268.

Dreyfus, H. L., \& Taylor, C. (2015). Retrieving realism. Cambridge, MA: Harvard University Press.

Favela, L. H., \& Chemero, A. (2016). The animal-environment system. In Y. Coello \& M. H. Fischer (Eds.), Foundations of embodied cognition: Volume 1: Perceptual and emotional embodiment (pp. 59-74). Abingdon, UK: Routledge.

Fernandez, A. V. (2016). The subject matter of phenomenological research: Existentials, modes, and prejudices. Synthese, 194(9), 1-20.

Fuchs, T. (2011). The brain - A mediating organ. Journal of Consciousness Studies, 18(7-8), 196221.

Gallagher, S. (2011). Interpretations of embodied cognition. In W. Tschacher \& C. Bergomi (Eds.), The implications of embodiment: Cognition and communication (pp. 59-71). Exeter, UK: Imprint Academic.

Gallagher, S. (2015). Invasion of the body snatchers: How embodied cognition is being disembodied. The Philosophers' Magazine, April(2), 96-102.

Gallagher, S., \& Zahavi, D. (2012). The phenomenological mind. Abingdon, UK: Routledge.

Gallese, V., \& Lakoff, G. (2005). The brain's concepts: The role of the sensory-motor system in conceptual knowledge. Cognitive Neuropsychology, 22(3-4), 455-479.

Goldman, A., \& de Vignemont, F. (2009). Is social cognition embodied? Trends in Cognitive Sciences, 13(4), 154-159.

Guignon, C. (2009). The body, bodily feelings, and existential feelings: A Heideggerian perspective. Philosophy, Psychiatry, \& Psychology, 16(2), 195-199.

Haugeland, J. (1998). Mind embodied and embedded. In J. Haugeland, Having thought: Essays in the metaphysics of mind (pp. 207-237). Cambridge, MA: Harvard University Press 
Heidegger, M. (1962). Sein und Zeit. Trans. as Being and time. (J. Macquarrie \& E. Robinson, Trans.). New York, NY: Harper and Row.

Heidegger, M. (2001). Zollikoner Seminare: Protokolle - Zwiegespräche - Briefe. Trans. as Zollikon seminars: Protocols - conversations - letters. (F. Mayr, Trans.). (J. McCumber \& D. Kolb. Eds.). Evanston, IL: Northwestern University Press.

Heidegger, M. (2006). Sein und Zeit. Tübingen, Germany: Max Niemeyer Verlag.

Henry, M. (1975). Philosophie et phénoménologie du corps: Essai d'ontologie biranienne. Trans. as Philosophy and phenomenology of the body. (G. J. Etzkorn, Trans.). Den Haag, The Netherlands: Martinus Nijhoff.

Husserl, E. (1989). Ideen zu einer reinen Phänomenologie und phänomenologischen Philosophie. Zweites Buch. Phänomenologische Untersuchungen zur Konstitution. Trans. as Ideas pertaining to a pure phenomenology and to a phenomenological philosophy. Second book. Studies in the phenomenology of constitution. R. Rojcewicz \& A. Schuwer (Trans.). Dordrecht, The Netherlands: Kluwer Academic Publishers.

Hutto, D., \& Myin, E. (2013). Radical enactivism: Basic minds without content. Cambridge, MA: MIT Press.

Jeuk, A. A. (2017). Overcoming the disunity of understanding. META. Research in Hermeneutics, Phenomenology and Practical Philosophy, 9(2), 630-653.

Kant, I. (1956). Kritik der reinen Vernunft. (W. Weischedel, Ed.). Frankfurt am Main, Germany: Suhrkamp Verlag.

Kant, I. (1998). Kritik der reinen Vernunft. Trans. as Critique of pure reason. (P. Guyer \& A. W. Wood, Trans. \& Eds.). Cambridge, UK: Cambridge University Press.

Kiverstein, J., \& Clark, A. (2009). Introduction: Mind embodied, embedded, enacted: One church or many? Topoi, 28(1), 1-7.

Kiverstein, J. (2012). The meaning of embodiment. Topics in cognitive science, 4(4), 740-758.

Kiverstein, J., \& Miller, M. (2015). The embodied brain: Towards a radical embodied cognitive neuroscience. Frontiers in human neuroscience, doi:10.3389/fnhum.2015.00237

Lakoff, G., \& Johnson, M. (1999). Philosophy in the flesh: The embodied mind and its challenge to western thought. New York, NY: Basic Books.

Mandik, P., \& Clark, A. (2002). Selective representing and world-making. Minds and Machines, 12(3), 383-395.

Merleau-Ponty, M. (2012). Phénoménologie de la perception. Trans. as Phenomenology of Perception. (D. A. Landes, Trans.). Abingdon, UK: Routledge.

Noë, A. (2004). Action in perception. Cambridge, MA: MIT Press.

Noë, A. (2005). Against intellectualism. Analysis, 65(288), 278-290. 
Noë, A. (2007). The critique of pure phenomenology. Phenomenology and the cognitive sciences, 6(1-2), 231-245.

Noë, A. (2009). Out of our heads: Why you are not your brain, and other lessons from the biology of consciousness. New York, NY: Hill and Wang.

Noë, A. (2012). Varieties of presence. Cambridge, MA: Harvard University Press.

de Oliveira, G. S., \& Chemero, A. (2015). Against smallism and localism. Studies in Logic, Grammar and Rhetoric, 41(54), 9-23.

O’Regan, J. K., \& Noë, A. (2001). A sensorimotor account of vision and visual consciousness. Behavioral and Brain Sciences, 24(05), 939-973.

Overgaard, S. (2004). Heidegger on embodiment. Journal of the British Society for Phenomenology, $35(2), 116-131$.

Overgaard, S. (2005). Being there: Heidegger's formally indicative concept of "Dasein". New Yearbook for Phenomenology and Phenomenological Philosophy, 5, 145-163.

Petitot, J., Varela, F., Pachoud, B., \& Roy, J-M. (Eds.) (1999). Naturalizing phenomenology: Issues in contemporary phenomenology and cognitive science. Stanford, CA: Stanford University Press.

Putnam, H. (1975). The meaning of "meaning”. Minnesota Studies in the Philosophy of Science, 7, 131-193.

Rietveld, E., \& Kiverstein, J. (2014). A rich landscape of affordances. Ecological Psychology, 26(4), $325-352$.

Rowlands, M. (2010). The new science of the mind: From extended mind to embodied phenomenology. Cambridge, MA: MIT Press.

Sartre, J.-P. (1962). Esquisse d'une théorie des émotions. Trans. as A sketch of a theory of emotions. (P. Mairet, Trans.). London, UK: Methuen Publishing.

Silberstein, M., \& Chemero, A. (2012). Complexity and extended phenomenological-cognitive systems. Topics in Cognitive Science, 4(1), 35-50.

Silberstein, M., \& Chemero, A. (2015). Extending neutral monism to the hard problem. Journal of Consciousness Studies, 22(3-4), 181-194.

Stapleton, M. (2013). Steps to a "properly embodied" cognitive science. Cognitive Systems Research, 22-23, 1-11.

Taipale, J. (2014). Phenomenology and embodiment: Husserl and the constitution of subjectivity. Evanston, IL: Northwestern University Press.

Thompson, E. (2007). Mind in life: Biology, phenomenology, and the sciences of mind. Cambridge, MA: Harvard University Press.

Thompson, E. (2011). Living ways of sense making. Philosophy Today, 55(Supplement), 114-123. 
Thompson, E., \& Cosmelli, D. (2011). Brain in a vat or body in a world? Brainbound versus Enactive Views of Experience. Philosophical Topics, 39(1), 163-180.

Thompson, E., \& Stapleton, M. (2009). Making sense of sense-making: Reflections on enactive and extended mind theories. Topoi, 28(1), 23-30.

van den Herik, J. (2014). Why radical enactivism is not radical enough: A case for really radical enactivism (Unpublished Master's thesis). University of Rotterdam, Faculty of Philosophy.

Varela, F., Thompson, E., \& Rosch, E. (1991). The embodied mind: Cognitive science and human experience. Cambridge, MA: MIT Press.

Vörös, S., Froese, T., \& Riegler, A. (2016). Epistemological odyssey: Introduction to special issue on the diversity of enactivism and neurophenomenology. Constructivist Foundations, 11(2), 189204.

Vörös, S., \& Gaitsch, P. (2016). The horizons of embodiment: Introduction to the special issue. Phainomena, 25(98-99), 5-32.

Wheeler, M. (2005). Reconstructing the cognitive world: The next step. Cambridge, MA: MIT Press.

Wheeler, M., \& Kiverstein, J. (Eds.) (2012). Heidegger and cognitive science. Basingstoke, UK: Palgrave Macmillan.

Wilson, M. (2002). Six views of embodied cognition. Psychonomic Bulletin \& Review, 9(4), 625-636.

Zahavi, D. (2005). Subjectivity and selfhood: Investigating the first-person perspective. Cambridge, MA: MIT Press.

Zahavi, D., \& Overgaard, S. (2012). Time, space and body in Bergson, Heidegger and Husserl. In R. Baiasu, G. Bird, \& A. Moore (Eds.), Contemporary Kantian metaphysics: New essays on space and time (pp. 270-297). Basingstoke, UK: Palgrave Macmillan. 